\title{
Sputtered Non-Hydrogenated Amorphous Silicon as Alternative Absorber for Silicon Photovoltaic Technology
}

\author{
Susana Fernández ${ }^{1, * \mathbb{C}}$, J. Javier Gandía ${ }^{1}$, Elías Saugar ${ }^{1}, \mathrm{M}^{\mathrm{a}}$ Belén Gómez-Mancebo ${ }^{2}$, David Canteli ${ }^{3}$ (D) \\ and Carlos Molpeceres ${ }^{3}$ \\ 1 Departamento de Energía, CIEMAT, Avd. Complutense 40, 28040 Madrid, Spain; jj.gandia@ciemat.es (J.J.G.); \\ elias.saugar@ciemat.es (E.S.) \\ 2 División de Química, CIEMAT, Avda. Complutense 40, 28040 Madrid, Spain; mariabelen.gomez@ciemat.es \\ 3 Centro Láser, Universidad Politécnica de Madrid-Campus Sur, Alan Turing 1, 28031 Madrid, Spain; \\ david.canteli@upm.es (D.C.); carlos.molpeceres@upm.es (C.M.) \\ * Correspondence: susanamaria.fernandez@ciemat.es; Tel.: +34-9134-66039
}

Citation: Fernández, S.; Gandía, J.J.; Saugar, E.; Gómez-Mancebo, M.B.; Canteli, D.; Molpeceres, C. Sputtered Non-Hydrogenated Amorphous Silicon as Alternative Absorber for Silicon Photovoltaic Technology. Materials 2021, 14, 6550. https:// doi.org/10.3390/ma14216550

Academic Editor: Johann Bouclé

Received: 30 September 2021

Accepted: 28 October 2021

Published: 1 November 2021

Publisher's Note: MDPI stays neutral with regard to jurisdictional claims in published maps and institutional affiliations.

Copyright: (c) 2021 by the authors. Licensee MDPI, Basel, Switzerland. This article is an open access article distributed under the terms and conditions of the Creative Commons Attribution (CC BY) license (https:/ / creativecommons.org/licenses/by/ $4.0 /)$.

\begin{abstract}
Non-hydrogenated amorphous-silicon films were deposited on glass substrates by Radio Frequency magnetron sputtering with the aim of being used as precursor of a low-cost absorber to replace the conventional silicon absorber in solar cells. Two Serie of samples were deposited varying the substrate temperature and the working gas pressure, ranged from 0.7 to $4.5 \mathrm{~Pa}$. The first Serie was deposited at room temperature, and the second one, at $325^{\circ} \mathrm{C}$. Relatively high deposition rates above $10 \AA$ /s were reached by varying both deposition temperature and working Argon gas pressure to ensure high manufacturing rates. After deposition, the precursor films were treated with a continuous-wave diode laser to achieve a crystallized material considered as the alternative light absorber. Firstly, the structural and optical properties of non-hydrogenated amorphous silicon precursor films were investigated by Raman spectroscopy, atomic force microscopy, X-ray diffraction, reflectance, and transmittance, respectively. Structural changes were observed in the as-deposited films at room temperature, suggesting an orderly structure within an amorphous silicon matrix; meanwhile, the films deposited at higher temperature pointed out an amorphous structure. Lastly, the effect of the precursor material's deposition conditions, and the laser parameters used in the crystallization process on the quality and properties of the subsequent crystallized material was evaluated. The results showed a strong influence of deposition conditions used in the amorphous silicon precursor.
\end{abstract}

Keywords: non-hydrogenated amorphous silicon; alternative light absorbers; magnetron sputtering; low-cost processing; photovoltaic technology

\section{Introduction}

Silicon is by far the most common material used in solar cells, resulting in a key piece for the photovoltaic industry; it is the second most abundant material on Earth, is non-toxic, and shows high stability and durability [1-4]. Accordingly, the photovoltaic sector is dominated by wafer-based crystalline silicon (c-Si) and multi-crystalline silicon (mc-Si) solar cells, with a throughput about $20-25 \%$. In fact, $90 \%$ of the manufactured solar cells are based on these technologies [5]. Despite the dramatic cost reduction undergone by monoand mc-Si wafers in the last decade, the further gain in competitiveness of photovoltaic devices requires intensive search for new approaches in what concerns semiconductor devices. The road to find new both solutions and forms of silicon goes through thickness reduction, kerf avoidance, and/or manufacturing cost lowering. Nowadays, the main efforts are focused on searching new cheap alternatives capable to replace above technologies. Although Czochralski (Cz) method is a well-known to obtain high quality c-Si wafer of around $100 \mu \mathrm{m}$-thick, it is a costly process that implies a high material consumption [6]. Therefore, the fabrication of thin films of polycrystalline silicon (poly-Si) $(\leq 40 \mu \mathrm{m})$ from 
non-hydrogenated amorphous silicon (a-Si) as precursor layer is very promising [7-9]. This poly-Si shows several advantages in comparison with the $\mathrm{Cz}$ technique, including the significant saving in material [10]. Liquid phase crystallization (LPC) of silicon is a promising method to achieve high quality thin-film poly-Si from the crystallization of a-Si thin films deposited on glass by using continuous wave diode laser or electron beam [7,11]. LPC technology offers an alternative solution to the well-established $\mathrm{Cz}$ method. In this sense, several works have already demonstrated excellent results using LPC silicon absorber on glass, with efficiencies up to $14.8 \%$ and short circuit voltages higher than $600 \mathrm{mV}[12,13]$. However, this silicon precursor is fabricated by high-rate electron beam evaporation or by plasma-enhanced chemical vapor deposition (PECVD) at elevated substrate temperatures as high as $600{ }^{\circ} \mathrm{C}$ [14] or using post-deposition treatments at temperatures at temperatures as high as $1000^{\circ} \mathrm{C}$ [15], which still implies a high energy consumption.

In the last decades, a-Si is gaining importance due to its advantages versus c-Si: (i) it is more absorbent in the visible wavelength (band gap energy of $1.7 \mathrm{eV}$ vs. $1.1 \mathrm{eV}$, respectively) and (ii) its absorption coefficient is one order of magnitude higher, leading to a thickness reduction [16]. Hence, its use allows both energy and material saving. Another important advantage with respect to other materials is its low deposition temperature that permits the use of flexible and lightweight substrates over the conventional c-Si. In addition, it is well-known that the growth process and the conditions used in the fabrication of the precursor material could affect the properties of the subsequent laser crystallized material. Thus, it is essential to firstly evaluate the quality and the nature of the precursor material before carrying out the laser process.

Considering the above, this work presents an analysis of the suitability of the nonhydrogenated a-Si precursor layers fabricated by radio frequency (RF) magnetron sputtering at a low-temperature regimen. This deposition technique shows several advantages such as to allow (i) depositing a-Si films from an inexpensive doped silicon ( $\mathrm{Si}$ ) target, (ii) using an inert gas (Ar) to avoid toxic gases as silane, (iii) not using high temperature regimes as techniques such as electron beam, and (iv) achieving deposition rates higher than other deposition methods (i.e., Plasma-Enhanced Chemical Vapor Deposition, PECVD [17]). The effects of the deposition conditions on the a-Si precursor properties (i.e., structure/nature, refractive index and/or band gap energy) and on the subsequent crystallized layers (i.e., grain size, crystalline faction) are studied. We are looking for a precursor material fabricated at moderate temperature (not higher than $325^{\circ} \mathrm{C}$ ) with a cost-effective technique, without needing high temperature processes, except the unavoidable step of laser treatment, and at fabrication conditions that trigger the LPC. Such an achievement can be considered quite relevant to obtain suitable precursors fabricated at a low energy consumption regime.

\section{Materials and Methods}

The non-hydrogenated a-Si thin films were deposited on glass (3 mm-thick Borofloat ${ }^{\circledR}$ 33 and Corning Eagle $X G^{\circledR}$ coated with a $200 \mathrm{~nm}$-thick $\mathrm{SiO}_{2}$, that favors the subsequent crystallization process) substrates using a commercial single chamber magnetron sputtering MVSystem with one cathode, vertically adjustable, operated by RF power. The distance between the target-substrate was set to $6.1 \mathrm{~cm}$. The 3 inch-size diameter p-Si target (Si) came from Lesker Company (St. Leonards-on-Sea, East Sussex, UK)) with a purity of $99.999 \%$, a resistivity of $0.005-0.020 \Omega \cdot \mathrm{cm}$ and a density of $2.32 \mathrm{~g} / \mathrm{cm}^{3}$. The control of the substrate temperature was performed by a type $\mathrm{K}$ reference thermocouple. Prior to load the substrates into the chamber, they were cleaned by using ultrasonic baths, rinsed in deionized water, and dried by blown nitrogen. Prior to the sputtering deposition, the base pressure of the chamber was around to $3 \times 10^{-4} \mathrm{~Pa}$. The a-Si precursor films were deposited at the different RF powers of $525 \mathrm{~W}$ and $450 \mathrm{~W}$, at the substrate temperatures of room temperature (RT) and $325^{\circ} \mathrm{C}$ and at the working gas argon (Ar) pressure ranged from 0.7 to $4.5 \mathrm{~Pa}$ that corresponded to an Ar flux of 17 to $70 \mathrm{sccm}$, respectively. These deposition conditions were chosen to obtain the highest possible deposition rate allowed 
by the sputtering system, and to look for compact layers, in agreement with Thornton model [18].

The crystallization process of the a-Si precursor was carried out with a continuouswave $(C W)$ diode laser emitting at $940 \mathrm{~nm}$ with a spot at focus of $16.5 \mathrm{~mm} \times 2.16 \mathrm{~mm}$. This spot is linear along the $X$ axis and Gaussian in the $Y$ axis. In addition, to reduce the possible thermal stress caused by this process and to prevent the possible resultant film cracking, the a-Si layers were previously heated at the high temperature of $650{ }^{\circ} \mathrm{C}$ on a heating table. After that, the samples were moved in a straight line at a constant scanning speed ranged from 400 to $1000 \mathrm{~nm} / \mathrm{min}$, and a laser irradiance was varied from $900 \mathrm{~J} / \mathrm{cm}^{2}$ and $1650 \mathrm{~J} / \mathrm{cm}^{2}$ were used.

The structural properties and morphology of a-Si films and the subsequent crystallized material were studied by Raman Spectroscopy, X-ray Diffraction (XRD), and Atomic Force Microscopy (AFM), respectively. A deeper morphological study was also carried out by micro-X-ray diffraction ( $\mu$ XRD) to obtain more information about the micro-structural nature of the precursor films. The Raman spectra were measured with a Micro-Raman LabRam HR Evolution (Tulln, Austria) with a HeNe at $632.81 \mathrm{~nm}$ laser as excitation source. XRD patterns were collected by using a PANalytical X'Pert Pro diffractometer operating in $\theta-2 \theta$ configuration, with $\mathrm{CuK} \alpha$ radiation $(45 \mathrm{kV}-40 \mathrm{~mA})$, in the angular range of $20^{\circ}<2 \theta<80^{\circ}$. Phase identification was obtained by comparison with The Inorganic Crystal Structure Database (ICDS). The surface morphology was analyzed by using a standard AFM Multimode Nanoscope III-A SPM from Veeco-Digital Instruments (Cambridgeshire, UK) operating in tapping mode. The roughness was quantified by the Root Mean Square (RMS) deviation of the AFM measured height from the mean data plane in the $5 \times 5 \mu \mathrm{m}^{2}$ images. Images were also taken in smallest areas of $1 \times 1 \mu \mathrm{m}^{2}$.

Finally, the specular transmittance $(\mathrm{T})$ and reflectance $(\mathrm{R})$ spectra of the as-deposited samples were obtained with a Perkin-Elmer Lambda 1050 UV/Visible/NIR spectrophotometer (Waltham, MA, USA), illuminating from the film side. From these data, film thickness $(d)$, refraction index (n), and absorption coefficient $(\alpha)$ were obtained by using a home-software. By means of the Tauc-plot of the absorption coefficient, the energy gap $\left(\mathrm{E}_{\mathrm{G}}\right)$ was extracted.

\section{Results}

3.1. Sputtering Deposition of Low-Temperature Non-Hydrogenated Amorphous Silicon (Precursor)

Two set of samples of $\sim 1.2 \mu$ m-thick samples were deposited at RT and $525 \mathrm{~W}$ of RF power (Series A), and at $325^{\circ} \mathrm{C}$ and $450 \mathrm{~W}$ of RF power (Series B), varying working gas pressure from 0.7 to $4.5 \mathrm{~Pa}$. Table 1 described the conditions used in the samples in studied.

Table 1. Summarize of the conditions used in the a-Si thin films deposited.

\begin{tabular}{cccc}
\hline Code Sample & $\begin{array}{c}\text { Substrate } \\
\text { Temperature }\left({ }^{\circ} \mathbf{C}\right)\end{array}$ & RF Power (W) & Pressure (Pa) \\
\hline A 1 & RT & 525 & 1.1 \\
A 2 & RT & 525 & 3.2 \\
A 3 & RT & 525 & 4.5 \\
B 1 & 325 & 450 & 0.7 \\
B 2 & 325 & 450 & 1.6 \\
B 3 & 325 & 450 & 2.7 \\
B 4 & 325 & 450 & 4.0 \\
\hline
\end{tabular}

The deposition conditions were optimized to reach deposition rates above $10 \AA$ s. Figure 1 shows the dependence of the deposition rate with the working Ar pressure for the Series A and B, depicted by red filled circles and black filled square, respectively. 


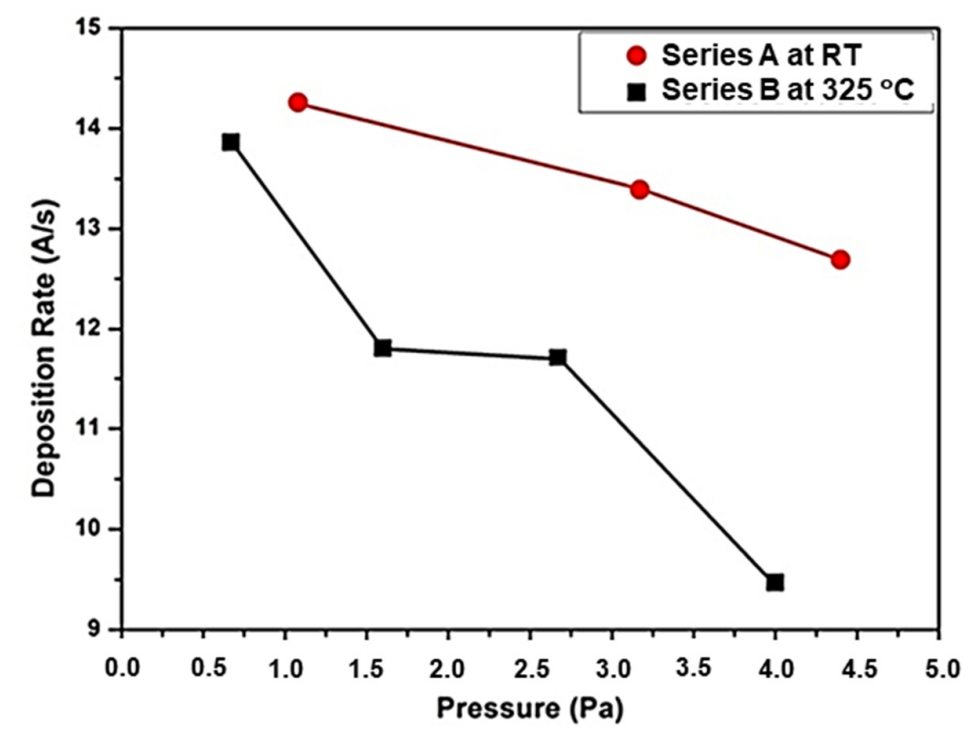

Figure 1. Deposition rate versus working Ar pressure for a-Si films deposited at RT (red symbols) and at $325^{\circ} \mathrm{C}$ (black symbols).

As it can be observed, the deposition rate linearly decreased with the Ar pressure in both Series, being, in the most cases, superior to $10 \AA$ /s. This value was higher than that achieved with other depositions methods such as PECVD [16]. The decreasing behavior of that parameter was expected due to the reduction in the mean free path of the species in the plasma when the gas pressure raised. The main mechanism responsible of that behavior was the increase in the collisions between the sputtered particles and the charged Ar ions [19].

The structural properties of the deposited a-Si films were investigated by Raman spectroscopy. Figure 2 depicts the Raman spectra of the samples of (a) Series A and (b) Series B.

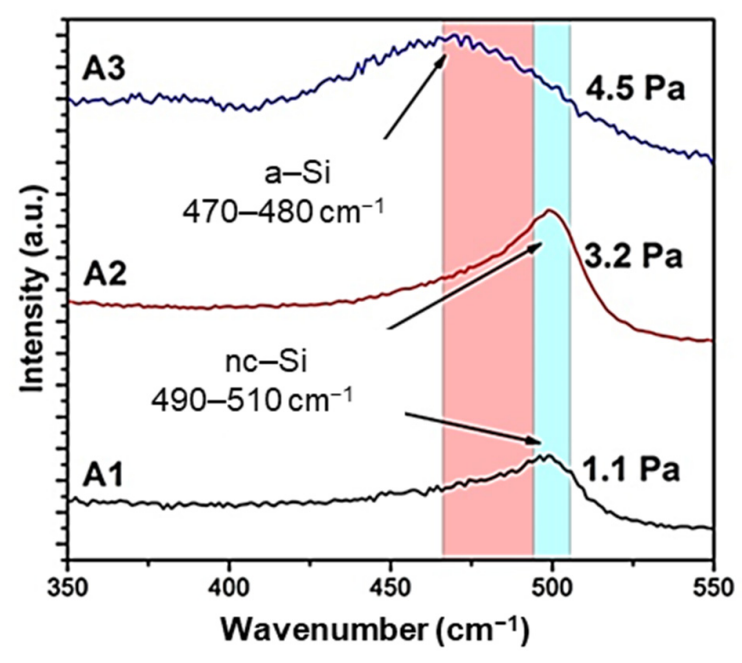

(a)

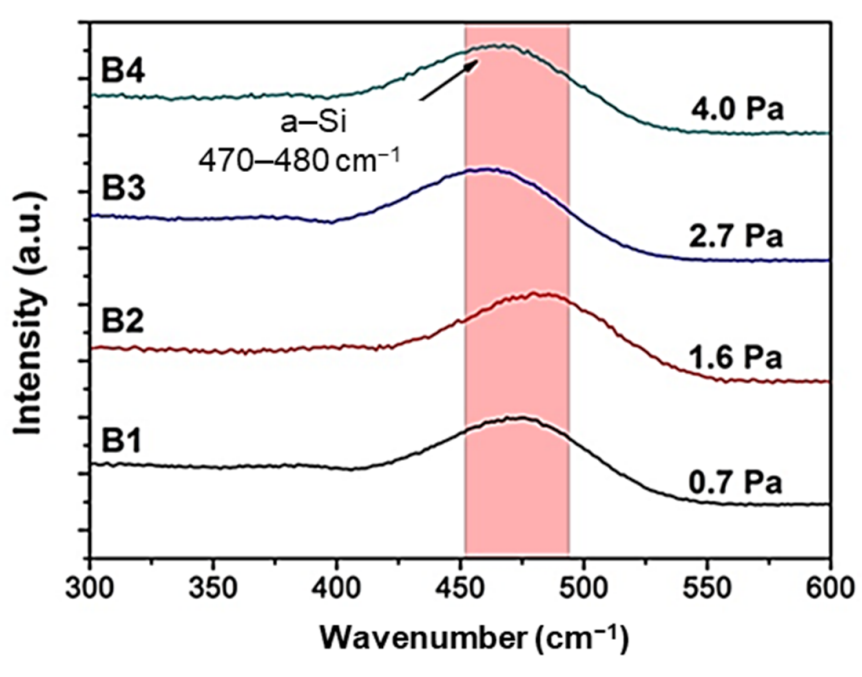

(b)

Figure 2. Raman spectra of the samples of: (a) Series A deposited at RT; (b) Series B deposited at $325^{\circ} \mathrm{C}$.

These spectra were fitted at four main bands [20,21]: A broad band centered at the wavenumber of $\sim 480 \mathrm{~cm}^{-1}$ that corresponded to an amorphous nature, that one at the wavenumbers of 500-510 $\mathrm{cm}^{-1}$, related to a nano-crystalline (nc) structure, the band at 510-520 $\mathrm{cm}^{-1}$, related to a polycrystalline (pc) material, and the last one at $520 \mathrm{~cm}^{-1}$, corresponding to the single crystal silicon. 
Raman spectra of Series A samples revealed a structural transition from nanocrystalline to amorphous nature as the Ar pressure increased. At the low Ar pressure regimen used, the Si-Si transverse optical mode (TO) was located at $500 \mathrm{~cm}^{-1}$, corresponded to nc-Si. This nc nature could be attributed to the higher impact of the sputtered ions on the substrate surface yielded at low Ar pressures [19]. In addition, the films deposited at these conditions of RT and low pressures would show a compact structure die to the high deposition rate, favoring to a better structural quality and to the presence of such nc structures. However, as the Ar pressure raised, more collisions were promoted in the plasma between the energetic Ar ions and the sputtered atoms that would lose part of its energy impacting much softer on the surface substrate [22]. Thus, the atoms would have lower kinetic energy, not enough to achieve a crystalline structure. To determine semi quantitatively the crystalline volume fraction $X_{C}$, the ratio of the integrated scattering intensity of the crystalline phase to the total scattering intensity was calculated from Raman spectra, according with the following equation [23]:

$$
X_{C}=\frac{I_{500-510}}{\left(I_{500-510}+I_{480}\right)},
$$

where $I$ is the area of the Gaussian peaks fitted to the spectra. The $X_{C}$ values calculated were $20 \%$ and $17 \%$ for the samples $\mathrm{A} 1$ and $\mathrm{A} 2$, respectively.

On the other hand, the Raman spectra of Series B samples showed a completely amorphous nature, where the $\mathrm{Si}-\mathrm{Si}$ TO appeared at the wavenumber band of $470-480 \mathrm{~cm}^{-1}$. This behavior goes against what has been observed in the literature, where the films deposited at high temperatures are denser, with an enhanced structural quality, and smoother surfaces due to both the high kinetic energy and the high surface diffusion [24]. A possible explanation for that unusual behavior would be that the samples of Series B were deposited at lower deposition rate and RF powers than samples of Series A. Hence, although the sputtered atoms in Series B would have enhanced surface diffusion due to the high substrate temperature, this would not be large enough to form an nc phase and to compensate the difference in the kinetic energy, as it would be happening in the samples of Series A.

To corroborate the structural and morphological difference between both as-deposited series, a deeper study using micro X-ray diffraction ( $\mu$ XRD) was carried out. This technique permits to observe slight changes that are not possible with other configurations. Representative XRD patterns of Series A and B are shown in Figure 3.
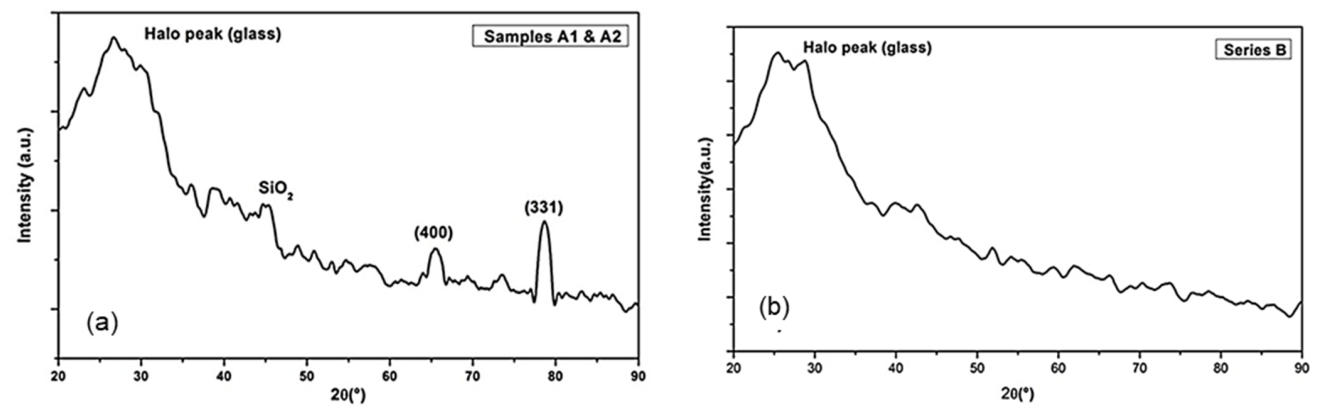

Figure 3. $\mu$ XRD patterns of samples of Series: (a) A deposited at RT; (b) Series B deposited at $325^{\circ} \mathrm{C}$.

Despite the deposition of Series B was carried out at relatively high temperature, the patterns (Figure $3 \mathrm{~b}$ ) did not present significant peaks. The broad band at $\sim 25^{\circ}$ was attributed to an amorphous structure [21]. Other authors as Cheng et al. and Jun et al. [25,26] reported an improvement of the crystallinity with increasing the substrate temperature from RT (completely amorphous) to $900{ }^{\circ} \mathrm{C}$ ((111), (220), and (331) crystal planes of silicon), although in these works the RF power applied $(1200 \mathrm{~W})$ [23] or the tested temperatures (from 600 to $900{ }^{\circ} \mathrm{C}$ ) [26] were completely differed from the used ones in this work. This may be due to the combination of RF power and substrate temperature $\left(450 \mathrm{~W}\right.$ and $\left.325^{\circ} \mathrm{C}\right)$ 
that could not be high enough to improve the crystallinity of the as-deposited samples, and hence, the increase in the working pressure would not have any observable effect on these samples. However, in the XRD patterns of the samples of Series A (samples A1 and A2) (Figure 3a), three pronounced diffraction peaks can be noticed at $2 \theta \cong 45.3^{\circ}, 65.6^{\circ}$, and $78.6^{\circ}$, which corresponded to $\mathrm{SiO}_{2}$ peaks, and (400) and (331), to crystal planes of silicon [24], indicative of a possible ordered structure embedded in an amorphous matrix. The $\mathrm{SiO}_{2}$ peak was attributed to the surface native oxide, which is probably presented but masked in the spectra of the amorphous films. Y. Qin et al. [27] reported previously that the samples deposited at RT and at different RF powers no present significant XRD peaks. However, in this work, it is possible to see an evolution from amorphous to crystallinity by the effect of pressure, although this effect was not observed in the sample at higher pressure (A3), probably as the pressure was too high.

Figure 4 depicts the 2D AFM micrographs of samples of (a) Series A and (b) Series B. A clear mounded morphology with an appreciable coarsening process was observed on the surface of the amorphous samples, resulting more evident in the samples deposited at $325^{\circ} \mathrm{C}$. On the other hand, spherical and uniform grains on the surface of the samples A1 and $\mathrm{A} 2$ were observed.

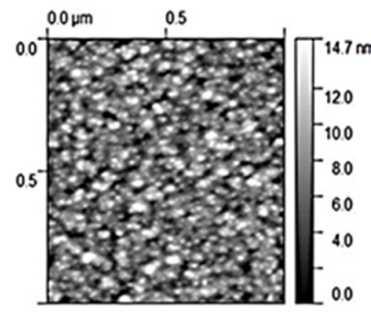

$4.5 \mathrm{~Pa}$

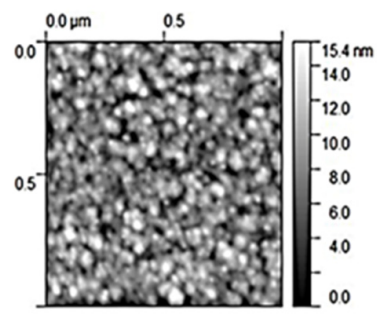

$3.2 \mathrm{~Pa}$

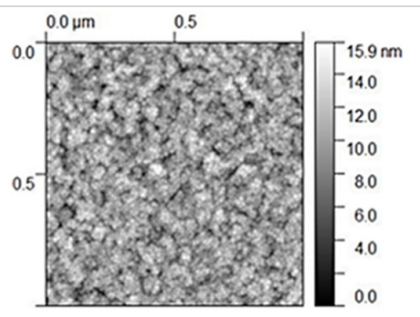

4.0 Pa

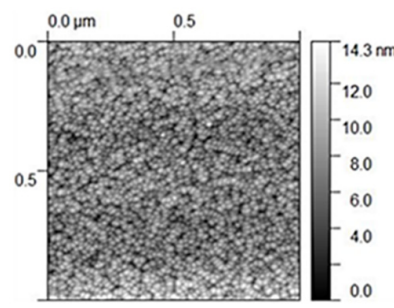

$1.6 \mathrm{~Pa}$

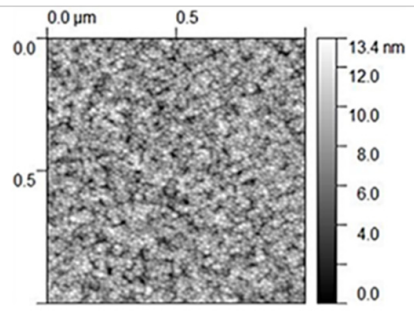

$2.7 \mathrm{~Pa}$

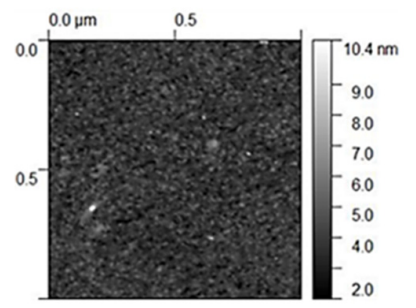

$0.7 \mathrm{~Pa}$

\section{(a)}

(b)

Figure 4. AFM $1 \times 1 \mu \mathrm{m}^{2}$ 2D micrographs of samples of Series: (a) A deposited at RT; (b) B deposited at $325^{\circ} \mathrm{C}$.

Table 2 summarizes the RMS values for both Series measured in the $5 \times 5 \mu \mathrm{m}^{2}$ AFM micrographs. The results indicated that smoother surfaces were obtained at low working pressures and at high substrate temperature (Series B). The change in the RMS values could be explained as the working pressure increased; the films tended to be rougher, led to a columnar microstructure, in agreement with the Thornton's structure zone model (SZM) [18].

Regarding the optical parameters of a-Si films, the electronic structure and band tails make the $\mathrm{E}_{\mathrm{G}}$ not have an accurate definition but having a value close to $1.7 \mathrm{eV}$ for the hydrogenated material (a-Si: H) [21] and $1.5 \mathrm{eV}$ for non-hydrogenated one [26]. To define the optical band gap transition of amorphous semiconductors between valence and conduction bands can be used the Tauc's equation [28].

$$
(\alpha E)^{1 / 2}=B\left(E-E_{G}\right)
$$

where $\alpha$ is the absorption coefficient, $E$, the photon energy and $B$, a constant called band tailing parameter. Table 3 shows the optical parameters calculated such as the band gap 
energy $E_{G}$, obtained from equation (1), and the refractive index at $1 \mathrm{eV}$, for the samples of both Series.

Table 2. RMS values of a-Si thin films obtained from $5 \times 5 \mu \mathrm{m}^{2}$ AFM 2D micrographs as a function of the working pressure.

\begin{tabular}{ccc}
\hline Code Sample & Pressure (Pa) & RMS (nm) \\
\hline A 1 & 1.1 & 1.63 \\
A 2 & 3.2 & 1.89 \\
A 3 & 4.5 & 1.93 \\
B 1 & 0.7 & 0.64 \\
B 2 & 1.6 & 0.69 \\
B 3 & 2.7 & 1.20 \\
B 4 & 4.0 & 1.25 \\
\hline
\end{tabular}

Table 3. Optical parameters of a-Si thin films as a function of the working pressure.

\begin{tabular}{cccc}
\hline Code Sample & Pressure $(\mathbf{P a})$ & $\boldsymbol{E}_{\boldsymbol{G}}(\mathbf{e V})$ & $\mathbf{n} @ \mathbf{1} \mathbf{~ e V}$ \\
\hline A 1 & 1.1 & 1.18 & 3.75 \\
A 2 & 3.2 & 1.35 & 3.40 \\
A 3 & 4.5 & 1.36 & 3.17 \\
B 1 & 0.7 & 1.42 & 3.60 \\
B 2 & 1.6 & 1.37 & 3.65 \\
B 3 & 2.7 & 1.47 & 3.70 \\
B 4 & 4.0 & 1.48 & 3.50 \\
\hline
\end{tabular}

A clear blue-shift in $\mathrm{E}_{\mathrm{G}}$ was observed for the samples of Series $\mathrm{A}$ with increasing the working pressure. This difference could be attributed to a change in the film structure, i.e., a possible ordered structure embedded in an amorphous matrix. In addition, at high working Ar pressures, the self-shadowing effects due to the lower mean free path due to the greater number of collisions produced in the plasma during the deposition, were more evident [29]. This would lead to the formation of more porous films, as demonstrated the lower value of the refractive index of the sample A3, of 3.17 in comparison to that calculated for samples A1 and A2. This would be consistent with the greater compactness derived from the presence of nanocrystals within an amorphous matrix, as the XRD and Raman spectra seem to suggest for those samples. Contrarily, no clear trend was observed in the $\mathrm{E}_{\mathrm{G}}$ and in the refractive index of the samples of Series $\mathrm{B}$, in agreement with the amorphous nature and similar morphology observed for all these samples.

At first sight, it could be thought that starting from an nc raw material could be advantageous for the subsequent crystallized material, and the nanocrystals could be acting as a seed. Taking this into account, the effects of (i) the substrate temperature, and (ii) the initial structure of the a-Si precursor on both the crystallization process and the main parameters of the crystallized material (i.e., crystalline fraction and grain size) are investigated in the next section.

\subsection{Effect of Deposition Conditions and Structure of the Precursor Material on the Subsequent Crystallized a-Si}

Table 4 describes the main parameters used in the crystallization process (i.e., irradiance and scan speed) on the precursor samples A1 and B2, with nanocrystalline and amorphous structure, respectively. The crystalline fraction $X_{C}$ was obtained from Raman spectra, using formula (1), and the grain size was calculated from the XRD patterns of the crystallized samples. 
Table 4. Parameters used in the crystallization process of a-Si films, and the crystalline fraction and grain size calculated in the crystallized samples.

\begin{tabular}{ccccc}
\hline Code Sample & Irradiance $\left(\mathbf{W} / \mathbf{c m}^{\mathbf{2}}\right)$ & Scan Speed $(\mathbf{n m} / \mathbf{m i n})$ & $\boldsymbol{X}_{\boldsymbol{C}}(\mathbf{\%})$ & Grain Size $(\mathbf{n m})$ \\
\hline A 1 & 950 & 400 & 84 & 50 \\
A 1 & 1220 & 600 & 84 & 71 \\
B 2 & 1385 & 1000 & 91 & 70 \\
B 2 & 1630 & 1000 & 96 & 2450 \\
\hline
\end{tabular}

The results reveal that the $X_{C}$ values for the crystallized zones of sample B2, deposited at the moderate temperature of $325^{\circ} \mathrm{C}$, were approximately $20 \%$ higher than for sample A1, deposited at RT. Note that B2 supported higher irradiance values during the crystallization process than A1 (see Table 4). In fact, sample A1 did not endure such high irradiance values, and as consequence, the molten material was not sticking to the substrate, suffering a strong peel-off and showing crystallized areas seriously damage. Therefore, the highest crystalline fraction of $84 \%$ obtained from A1 was not enough and the LPC was not reached. In addition, the grain size scarcely changed neither with the irradiance nor with the scan speed in the crystallized material using A1 as precursor, even though the raw material presented an nc structure embedded into an amorphous matrix. This limitation observed in the crystallization conditions applied on A1 was attributed to the low deposition temperature, having more weight than the fact of starting from a slight orderly structure. Such a result would be consistent with the finding that from raw material deposited at temperatures higher than RT led in a more effective way to the rearrangement of silicon atoms during the crystallization process, and hence, the LPC can be achieved more easily [12]. Furthermore, it can be observed that the grain size increased sharply from $70 \mathrm{~nm}$ to $\sim 2.5 \mu \mathrm{m}$ for the crystallized material from sample B2, reaching values of crystalline fraction higher than $95 \%$. This was consistent with the higher irradiance values allowed in the crystallization process of this sample.

In view of the results obtained, it can be concluded that the substrate temperature at which the raw material was deposited would have strong influence on the subsequent crystallization parameters used, and hence, on the capability of reaching the LPC. In this work, it has been demonstrated that high $X_{C}$ of $95 \%$ and grain size of the order of microns can be achieved from a completely amorphous raw material deposited at moderately high deposition temperature of $325^{\circ} \mathrm{C}$, which is still below what is used in other studies [12-14].

\section{Conclusions}

a-Si films were deposited by RF magnetron sputtering on glass substrates at different temperatures of RT and $325{ }^{\circ} \mathrm{C}$ and working gas pressures ranged from 0.7 to $4.5 \mathrm{~Pa}$. Under these conditions, high deposition rates $(>10 \AA / \mathrm{s})$ were reached. This data can be considered as an essential requirement for low-cost photovoltaic technology to fabricate cost-effective absorbers.

The Raman spectra and XRD patterns suggested an nc structure embedded in an amorphous matrix when the precursor samples were deposited at RT and relatively low process pressures up to $3.2 \mathrm{~Pa}$. These samples showed a preliminary crystalline fraction around $20 \%$, and the optical band gap and compactness obtained were closer to a crystalline material than to a purely amorphous one. Lastly, the AFM analysis revealed smoother surfaces when the precursor layers were deposited at the substrate temperature to $325^{\circ} \mathrm{C}$.

On the other hand, the characterization of the crystallized samples showed an improvement of the grain size $(\sim 2.5 \mu \mathrm{m})$ and the crystalline fraction $(94 \%)$ when starting from an a-Si precursor material deposited at the moderately high temperature of $325^{\circ} \mathrm{C}$. These results suggest the relevance of the substrate deposition to reach the LPC in the crystallization process, a key piece to achieve a suitable crystallized material. In addition, the laser processed samples offered better performance under high irradiances, regardless the sputtered conditions used in the precursor fabrication. Despite the precursor samples deposited 
at RT showed an initial nc structure, the values reached of the crystalline fraction and the grain size were very poor, and in any case, not superior to $84 \%$ and $71 \mathrm{~nm}$, respectively.

Finally, such an achievement reached using a precursor material deposited at so moderately substrate temperature could result very advantageous for the silicon technology. This fact could be an interesting choice to reduce the energy consumption in the device processing.

Author Contributions: Conceptualization, S.F., J.J.G. and C.M.; methodology, S.F., J.J.G. and C.M.; software, J.J.G. and E.S.; validation, S.F., E.S. and D.C.; formal analysis, E.S., D.C. and M.B.G.-M.; investigation, S.F. and D.C.; resources, J.J.G. and C.M.; data curation, E.S., D.C., M.B.G.-M., J.J.G. and S.F.; writing—original draft preparation, S.F. and E.S.; writing—review and editing, J.J.G., D.C. and M.B.G.-M.; project administration, J.J.G. and C.M.; funding acquisition, J.J.G. and C.M. All authors have read and agreed to the published version of the manuscript.

Funding: This research was funded by Ministerio de Ciencia e Innovación, grant number PID2019109215RB-C42 and PID2019-109215RB-C44 (SCALED).

Institutional Review Board Statement: Not applicable.

Informed Consent Statement: Not applicable.

Data Availability Statement: Not applicable.

Acknowledgments: The authors acknowledge the technical support in the Raman characterization given by L. Jiménez-Bonales and J. Cobos from CIEMAT; and also to Institute for Silicon Photovoltaics from Helmholtz-Zentrum for the substrates support used in the crystallization process.

Conflicts of Interest: The authors declare no conflict of interest.

\section{References}

1. El Chaar, L.; Iamont, L.A.; El Zein, N. Renewable of photovoltaic technologies. Renew. Sust. Energy Rev. 2011, 15, $2165-2175$. [CrossRef]

2. Parida, B.; Iniyan, S.; Goic, R. A review of solar photovoltaic technologies. Renew. Sust. Energy Rev. 2011, 15, 1625-1636. [CrossRef]

3. Yang, J.; Banerjee, A.; Guha, S. Amorphous silicon- based photovoltaics-From earth to the final frontier. Sol. Energy Mater. Sol. Cells 2003, 78, 597-612. [CrossRef]

4. Wilson, G.M.; Al-Jassim, M.; Metzger, W.K.; Glunz, S.W.; Verlinden, P.; Xiong, G.; Mansfield, L.M.; Stanbery, B.J.; Zhu, K.; Yan, Y.; et al. The 2020 photovoltaic technologies roadmap. J. Phys. D Appl. Phys. 2020, 53, 493001. [CrossRef]

5. Mauk, M.G. Chapter I-2-D-Thin Crystalline and Polycrystalline Silicon Solar Cells. In McEvoy's Handbook of Photovoltaics: Fundamentals and Applications; Academic Press: Cambridge, MA, USA, 2018; pp. 159-231. [CrossRef]

6. Bayod-Rújula, A.A. Chapter 8-Solar photovoltaics (PV). In Solar Hydrogen Production: Processes, Systems and Technologies; Academic Press: Cambridge, MA, USA, 2019; pp. 237-295. [CrossRef]

7. Haschke, J.; Amkreutz, D.; Rech, B. Liquid phase crystallized silicon on glass: Technology, material quality and back contacted heterojunction solar cells. Jpn. J. Appl. Phys. 2016, 55, 04EA04. [CrossRef]

8. Eisenhauer, D.; Trinh, C.T.; Amkreutz, D.; Becker, C. Light management in crystalline silicon thin-film solar cells with imprinttextured glass superstrate. Sol. Energy Mater. Sol. Cells 2019, 200, 109928. [CrossRef]

9. Sonntag, P.; Presissler, N.; Bokalic, M.; Trahms, M.; Haschke, J.; Schalatmann, R.; Topic, M.; Rech, B.; Amkreutz, D. Silicon solar cells on glass with power conversion efficiency above 13\% at thickness below 15 micrometer. Sci. Rep. 2017, 7, 873. [CrossRef] [PubMed]

10. Becker, C.; Amkreutz, D.; Sontheimer, T.; Preidel, V.; Lockau, D.; Haschke, J.; Jogschies, L.; Klimm, C.; Merkel, J.J.; Plocica, P.; et al. Polycrystalline silicon thin-film solar cells: Status and perspectives. Sol. Energy Mater. Sol. Cells 2013, 119, 112-123. [CrossRef]

11. Jia, G.; Andrä, G.; Gawlik, A.; Schönherr, S.; Plentz, J.; Eisenhawer, B.; Pliewischkies, T.; Dellith, A.; Falk, F. Nanotechnology enhanced solar cells prepared on laser-crystallized polycrystalline thin films $(<10 \mu \mathrm{m})$. Sol. Energy Mater. Sol. Cells 2014, 126, 62-67. [CrossRef]

12. Trinh, C.T.; Schalatmann, R.; Rech, B.; Amkreutz, D. Progress in and potential of liquid phase crystallized silicon solar cells. Sol. Energy 2018, 175, 75-83. [CrossRef]

13. Preissler, N.; Amkreutz, D.; Sonntag, P.; Trahms, M.; Schlatmann, R.; Rech, B. Inferface engineering for liquid-phase crystallizedsilicon solar cells on glass. Sol. RRL. Adv. Sci. News 2017, 1, 1700015. [CrossRef]

14. Amkreutz, D.; Haschke, J.; Häring, T.; Ruske, F.; Rech, B. Conversion efficiency and process stability improvement of electron beam crystallized thin film silicon solar cells on glass. Sol. Energy Mater. Sol. Cells 2014, 123, 13-16. [CrossRef]

15. Bailey, L.R.; Proudfoot, G.; Mackenzie, B.; Andersen, N.; Karlsson, A.; Ulyashin, A. High rate amorphous and crystalline silicon formation by pulsed DC magnetron sputtering deposition for photovoltaics. Phys. Stat. Sol. A 2015, 212, 42-46. [CrossRef] 
16. Sircar, R.; Tripathi, B.; Gupta, S. Design and simulation of thin-film silicon quantum well photovoltaic cell. J. Nano-Electron. Phys. 2011, 3, 11-18.

17. Moravej, M.; Babayan, S.E.; Nowling, G.R.; Yang, X.; Hicks, R.F. Plasma enhanced chemical vapor deposition of hydrogenated amorphous silicon at atmospheric pressure. Curr. Appl. Phys. 2010, 10, 5354-5356. [CrossRef]

18. Thornton, J.A. Influence of apparatus geometry and deposition conditions on the structure and topography of thick sputtered coatings. J. Vac. Sci. Technol. 1974, 11, 666-670. [CrossRef]

19. Hashim, S.B.; Mahzan, N.H.; Herman, S.H.; Rusop, M. Room-temperature deposition of silicon thin films by RF magnetron sputtering. Adv. Mater. Res. 2012, 576, 543-547. [CrossRef]

20. Choi, S.G.; Wang, S.-J.; Park, H.-H.; Jang, J.-N.; Hong, M.; Kwon, K.-H.; Park, H.-H. Properties of amorphous silicon thin films synthesized by reactive particle beam assisted chemical vapor deposition. Thin Solid Film. 2010, 518, 7372-7376. [CrossRef]

21. Müllerová, J.; Prusáková, L.; Netralová, M.; Vavrunková, V.; Sutta, P. A study of optical absorption in amorphous hydrogenated silicon thin films of varied thickness. Appl. Surf. Sci. 2010, 256, 5667-5671. [CrossRef]

22. Liu, K.; Yao, W.; Wang, D.; Ba, D.; Liu, H.; Gu, X.; Meng, D.; Du, G.; Xie, Y.; Ba, Y. A study of intrinsic amorphous silicon thin film deposited on flexible polymer substrates by magnetron sputtering. J. Non-Cryst. Solids 2016, 449, 125-132. [CrossRef]

23. Houben, L.; Lyusberg, P.; Hapke, R.; Carius, F.; Finger, F.; Wagner, H. Structural properties of microcrystalline silicon in the transition from highly crystalline to amorphous growth. Philos. Mag. A 1998, 77, 1447-1460. [CrossRef]

24. Alfonso, E.; Olaya, J.; Cubillos, G.I. Thin film growth through sputtering technique and its applications. In Crystallization-Science and Technology; IntechOpen: London, UK, 2012; Available online: https://www.intechopen.com/books/crystallization-scienceand-technology/thin-film-growth-through-sputteringtechnique-and-its-applications (accessed on 19 September 2012)ISBN 978-953-51-0757-6. [CrossRef]

25. Cheng, Q.; Xu, S.; Ostrikov, K.K. Structural evolution of nanocrystalline silicon thin films synthesized in high density, lowtemperature reactive plasmas. Nanotechnology 2009, 20, 215606. [CrossRef]

26. Jun, S.; Melechko, A.V.; Simpson, M.L. Low-temperature solid-phase crystallization of amorphous silicon thin films deposited by rf magnetron sputtering with substrate bias. Appl. Phys. Lett. 2006, 89, 022104. [CrossRef]

27. Qin, Y.; Feng, T.; Li, Z.; Sun, Z. Structural, optical and electrical properties of amorphous silicon thin films prepared by sputtering with different targets. Appl. Surf. Sci. 2011, 275, 7990-7996. [CrossRef]

28. Zanatta, A.R. Revisiting the optical bandgap of semiconductors and the proposal of a unified methodology to its determination. Sci. Rep. 2019, 9, 11225. [CrossRef] [PubMed]

29. Márquez, E.; Blanco, E.; García-Váquez, C.; Díaz, J.M.; Saugar, E. Spectroscopic ellipsometry study of non-hydrogenated fully amorphous silicon films deposited by room-temperature radio-frequency magnetron sputtering on glass: Influence of the argon pressure. J. Non-Cryst Solids. 2020, 547, 120305. [CrossRef] 